\title{
Oil Economy and Female Prostitution in Port Harcourt
}

\author{
C. Poroma ${ }^{1, a}$, U. J. David ${ }^{2, b}$, O. R. Jackson ${ }^{2, c}$ \\ ${ }^{1}$ Department of Social Studies, Ignatius Ajuru University of Education, Port Harcourt, Nigeria \\ ${ }^{2}$ Department of General Studies, Federal Polytechnic, Nasarawa, Nigeria \\ a,b,c E-mail address: porocele@yahoo.com , usmandave83@yahoo.com , \\ robinjakks@yahoo.co.uk
}

\begin{abstract}
The research directs attention to the relationship between oil economy and increase in female prostitution. Specifically, we x-ray the historical and dialectical origin of prostitution from the colonial to the post colonial era. We contend that, prostitution is a condition imposed on females from low income background by poverty and that oil exploration and exploitation activities which are a manifest consequence of the expanded reproduction of capital (ERC) accentuate the rate of prostitution particularly in Port Harcourt. It is against this backdrop that, we attempt to demystify the social processes and the dynamic relations that produce prostitution with a view to recommending theoretical and practical measures of curbing prostitution as a social problem.
\end{abstract}

Keywords: Oil Economy; Prostitution; Poverty and Classes

\section{INTRODUCTION}

Carmichael (1982) defines prostitution as the commoditization of sexual relations: sexual relations with the utilitarian value determined by the level of financial benefit. In agreement with Carmichaels' definition, Brett (1963) notes:

Prostitution is the offering by a female of her body commonly for acts of lewdness for payment although there is no act or offer as ordinary sexual connection.

That male prostitution exists is a known fact and has been accepted by a long tradition of social science (Scarpiti,1977), but male prostitution is comparatively infinitesimal to that of females. Prostitution is a universal phenomenon that is as old as society and can be traced even to the Bible (Joshua, 2:11; Hosea, 1:2 and Proverbs, 7:10). It is also not an aberration to some primitive groups amongst who are the Tanni Islanders of Polynesia and Pueblo Indians of New Mexico (Poplin,1978) and according to Westermarck (1980) to the natives of the Caroline, Melanesian Island and several other American Indian tribes. Furthermore, while prostitution is criminalized in the oriental world, the situation is compounded by its official recognition as a worthy profession in some Asian countries like China and Japan where parents sell their daughters into what is a recognized profession. 
However, countries theoretically abhor and frown at prostitution. The reasons for their castigation of prostitution are not far fetched.

i. Prostitution as a sexual arrangement is debasing to womanhood (Azunda, 1998)

ii. Commercial sex contribute immensely to the depletion of human resources which is a key factor in national development as infection rate of HIV and other deadly sexually transmitted diseases among prostitutes is high up to 18-52\% (Ebong,1998) and more recently 'Ebola' disease infection.

iii. That prostitution accentuates the divorce rate in the society: this is destructive as it negatively impact on the institution of the family, the major unit of production and socialization in the society (Arkutu, 1977).

These and a host of other factors propelled the second assembly of the United Nations Organization (UNO) to sign a treaty by thirty two(32) member states in 1991 abolishing slave trafficking and the business of prostitution.

Not withstanding the criminalization of prostitution in Nigeria as aptly reflected in the Criminal Procedure Act (1963) and consequent efforts by law enforcement agencies at curbing the trade, prostitution still flourish and has assumed the Italian - like multi-billion syndicate business with intricate local and international network.

All over Nigeria, countless girls exist soliciting for men, some patrolling streets and private offices almost nude while others are noted for positioning themselves at strategic points in school campuses, night clubs and hotel. The caption of many Nigerian newspapers which reads, "this call girl affairs", "these sex hungry women", "prostitutes fight customers", "lecturers in sex scandal with campus girls", "human trafficking for prostitution" and " city centers of Nigeria in siege by prostitutes are manifestation of the magnitude and concern for the problem. Emene (2012) captures more succinctly the intractable nature of prostitution in Port Harcourt thus:

\begin{abstract}
In Port Harcourt the nation's garden city, thousands of Nigerian girls and women like other nationals live in brothels doing business with their body: several others who may not live in brothels parade the streets in front of major hotels waiting to be picked by potential customers or men.
\end{abstract}

The local and international concern over the problem calls for urgent and practical measures at reversing the social trend. Adopting the political economy approach we contend that, prostitution is the alternative between survival and starvation in a capitalist oil dominated economy for females from the exploited class. It is a response to financial insecurity. The alarming trend of prostitution in Port Harcourt is a condition imposed by the innate contradictions of capitalist social relations in an oil dominated economy. Women and girls are impelled to become prostitutes to stay alive just as other exploited classes resort to other forms of deviant behavior.

\title{
1. 1. Hypothesis
}

For carrying out this study we hypothesized as follows:

a) That port Harcourt has witnessed a steady rise of prostitution in recent times

b) That oil and gas exploration activities accentuate prostitution in Port Harcourt

c) That there is a relationship between poverty and prostitution 
d) That children from lower income class families are prone to prostitution than children from middle or high income class families

\section{OPERATIONAL DEFINITION OF KEY TERMS}

The key variables or terms employed by the researcher are oil economy, prostitution, poverty and classes.

\section{1. Oil Economy}

Oil is defined as a thick liquid in rock underground. It is part of the mineral endowment that is used as fuel and to make parts of machine move freely. Economy on the other hand refers to that aspect of the society that deals with organizing, managing and reproducing material life (Akpuru, 1998). Oil economy therefore defines an economic system predicated on oil.

Today oil is Nigeria's most important economic resource. Oil is however in commercial quantity more in the Niger Delta region of the swamps, mangrove forest populated area of Nigeria with most oil multinationals and service companies located in Port Harcourt (Okoko and Nna, 1998) In fact the name Port Harcourt is the "Oil City'. It is therefore not surprising that oil and oil activities have impacted heavily on the behavioural pattern and values of the people particularly girls and women

\section{2. Prostitution}

It is the granting of sexual access on a relatively indiscriminate basis for payment in money or goods depending on the complexity of the local economic system. Therefore, the prostitute in this study is a female who enters into a sexual relation with a man or men for payment. The prostitute may be a young girl, a lady or even a woman, but the central determinant factor here is payment and agreement.

\section{3. Poverty}

Poverty defines a condition where people are incapable of providing $80 \%$ of their nutritional needs: where clothing, housing and education are a luxury. The poor may be a trader, businessman, civil servant or even a farmer.

\section{4. Classes}

Classes in this study refers to large groups of people differing from each other by income and political power derived from ownership and non-ownership of the means of production and status and political power based on the market values of professional skills acquired by individuals.

\section{INTERNATIONALIZATION OF CAPITALISM AND RISE OF PROSTITUTION}

Prostitution as a social problem is not an innovation, long before now various scholars have engaged in an endless debate on the definition, nature, dynamics and control measures of prostitution each bringing to bear his/her perspective. It is our intention to review these 
debates specifically with reference to the role of the expanded reproduction of capital and the rise prostitution.

Marx (1964) in the Economic and Philosophical Manuscript asserted that all forms of wage labour is a form of prostitution, that prostitution is only a specific expression of the general prostitution of the laborer. Marx thus views prostitution as a sort of alienated relationship "'created by capitalism, where money substitutes for concrete human characteristics"' (Ibid: 106). With reference to capitalism Marx declared:

\footnotetext{
'What I am and can do is, therefore, not at all determined by my individuality.

I am ugly, but I can buy the most beautiful woman for myself. Consequently, I am not ugly, for the effect of ugliness, its power to repel is annulled by money"' (1964:167).
}

Just as the capability of labor is commoditized under the capitalist mode of production, so also is sexuality, especially that of women. The prostitute like other laborers, have an essential part of them alienated, they are dehumanized and their value as persons determined by market forces.

Taylor (1988) arguing along the path of Marx and Engels stated that capitalism has inbuilt structures that create unemployment, inequality and hence poverty with consequences for prostitution. He noted that:
Multinational companies the engine of the capitalist system have shifted their activities from country to country in search for profit and their belief that mass production of standardized product is no longer viable for guaranteeing long term profit has created job insecurity and temporary unemployment.

The alarming rise of the rate of prostitution in Nigerian society is a reflection of perennial poverty, itself a direct consequence of the nature, dynamics and functioning of capitalism. Currie (1998) pointed out five main interlinked justifications why the operation of capitalism leads to high rate of prostitution thus:

i. Market societies promote prostitution by increasing inequality and concentrated economic development. The number of very well paid jobs has increased, but so are the numbers of very poorly paid and insecure jobs. Worse still, unions have become so weak to bargain effectively with their members. Faced with restricted opportunities to escape from poverty by legitimate means, the poor female increasingly turn to prostitution;

ii. Market society promote prostitution by eroding the capacities of local communities to provide 'informal support', mutual provision and effective socialization and supervision of the young poor as economic strain and social disorganization combine to produce high prostitution rate;

iii. Capitalism promotes prostitution by fragmenting the family;

iv. Capitalism promotes prostitution by withdrawing public basic services from those it has already stripped of the means of livelihood;

v. Capitalism promotes prostitution by magnifying and reinforcing a culture of Darwinism, competition for status and resources and urging of the level of consumption it can not provide for through legitimate means. 
No culture is insulated from others. Therefore, an understanding of the emergence of colonialism in Africa as an integral part of the expanded reproduction of capital will show the relationship between capitalism and the rate of prostitution in Nigeria.

There has been an endless argument whether prostitution is endogenous to traditional African societies or whether they resulted from Western influence. Sex and sex associated issues are held sacrosanct in most traditional African societies. The act was normally designed for procreation (Caplan, 1987), not necessarily for pleasure and recreation. This did not hamper unmarried people to practice sex, or even married men (not women) in many societies from practicing polygamy and keeping of concubines outside matrimony. This is in acknowledgement of the strong sex drive in every healthy man. Among the Kikuyu for instance, young boys and girls are usually permitted (well supervised) to practice sex short of full secretion to avoid pregnancy (Caplan,1987). Similar practices occurred in several traditional African societies usually associated with the rites of passage especially boys to adulthood.

However, modernization and western values changed the sexual values of Africans. Being less enamored by traditional values and norms, sexual relationship in the cities are by contrast with rural societies conceived as an individual matter. In the rural areas, sex is of wide concern and affects other people because of the premium placed on prostitution by the group as a whole. In cities however, the need for children is infinitesimal and sexual service have less relevance and tend to be regarded as a commodity obtainable by favor or bargaining (Little 1995). This does not however suggest that all urban women are sexually promiscuous or that all sexual relationships are commercial. The cities provided the sought after European goods and the women who acquired these were held in high esteem in many culture. Aqua's survey of Ghana in 1958 and Leslie's work in Dar es Salam (1963) revealed that urban prostitutes were accorded respect in the villages and have the opportunity of even going into respectable marriage on the basis of her proceeds. These include in addition to money, a sewing machine, gramophone, and records, bicycle and ornaments. Bryk (1964) captures it more succinctly:

\begin{abstract}
'the visit of the prostitute to the village is a big event. She brings bread, tea, sugar, and other foreign goods and items. She is the favorite of everybody and is quite popular. She was seen as a civilized person; exhibiting the ways of the whites"
\end{abstract}

The burning desire for materialism reinforces the desire for young girls to join this "nouveau riche", sophisticated and respected women. Bryk (1964) equally indicates of
"her first visit to her village/family brings new recruits for prostitution
- a flight of girls from the reservation where the rigors of the law
hamper the freedom of women's every movement, to the panagani
(Town) where the woman is happy and free. Even mothers in the
reservation are delighted by the career of her who has come to visit
them that they secretly harbor the wish that there daughters might
follow the example of the Mlaya",

A pertinent question here is whether all causes of prostitution can be reduced to colonialism and commercialization of Africa. Naanem (1986) had in a way showed that there is cultural dimension to prostitution. He wondered why all communities in Nigeria did not 
embrace prostitution like the cross River Basin. He revealed that there was disparity between Cross River Basin and other parts of Nigeria and pointed out that the area was not deeply incorporated into the colonial economy like the Cocoa producing areas of south West geopolitical zone and the palm belt area of Calabar. He locates high prostitution rate in the cross River Basin on matrilineal system of kinship and inheritance. This arrangement enslaved and victimized women. Prostitution in this area is therefore a response to the anachronistic system of male dominance in a dynamic world. Many women had to flee to the cities to escape male dominance. The tendency to prostitution is therefore innate in almost all cultures.

\section{THE IMPACT OF OIL AND GAS EXPLORATION ACTIVITIES ON PORT HARCOURT}

Port Harcourt was chosen for this study because it is host to a large number of prostitutes, involving married women, ladies, female students and even children prostitutes. Secondly, Nigeria is an oil economy and most of the oil and gas production and service companies have their head offices and locations in and around Port Harcourt. Thirdly, Port Harcourt has the highest number of expatriates outside Lagos. Furthermore, the number of jobs seekers far outstrips the available jobs opportunities in Port Harcourt. Again, outside Lagos and Abuja it has the highest number of restaurant, night clubs, hotels and guest houses were commercial sex activities revolves. It is equally worthy of note that, cost of living in Port Harcourt is very high only next to Abuja. Finally, cultural patterns, values and dressing patterns have changed tremendously, as materialistic values have eaten deep into the lives of dwellers

Port Harcourt is the capital of Rivers State, Nigeria. It lies along the Bonny River and is located in the Niger Delta. According to the 2006 Nigerian census Port Harcourt has a population of 1,382,592. Port Harcourt was named by Frederick Lugard after Lewis Vernon Harcourt in 1913 who was the Secretary of State for the Colonies. The colonial administration of Nigeria created the port to export coal from the collieries of Enugu located 151 miles $(243 \mathrm{~km})$ north of Port Harcourt, which it was linked to by a railway called the Eastern Line, also built by the British.

The discovery of oil and its boom accorded Port Harcourt a cosmopolitan status with serious economic, social, cultural and political consequences. An important aspect is in the area of rural urban migration. The pattern of migration to primate cities in Africa has been noted by authors like Asogwa (1997), little (1995), Ekpeyong (1992), Hannah and Hannah (1974) among many others. The rural people of the Niger Delta forced by declining fortune in agriculture, arising from the predominance of oil as the prime economic good and the devastation of farmlands and rivers due to pollution and negative consequences of oil activities, coupled with neglect by the oil companies had to migrate to Port Harcourt. Moreover, in 1950, Shell BP moved its industrial and industrial base from Owerri to Rumukrushi and Rumubiakani in Port Harcourt respectively. Consequently, people trooped to Port Harcourt in search of greener pastures. It must equally be noted that the benefit of oil wealth accrued only to a few well-placed class of people. Initially, only young men migrated to Port Harcourt in search of greener pastures. Little's work (1995) showed that there were three men to two women in African cities at independence. This is by far an improvement on the population ratio between men and women in cities at the onset of colonialism. Hannah and Hannah (1974) revealed how land tenure system and apartheid policy restricted women city 
ward migration. Such cities with preponderance of young men created artificial scarcity of sex such that urban men had to source for it with their money. It also involved enterprising young ladies migrating to the cities with less cultural and social restriction, selling their bodies for the resources it attracts. Young unmarried girls championed such city ward movement as the case with Bakiribe and Port Harcourt in Uganda and Nigeria respectively. The industrial urban economy set in motion structural changes that made most women to migrate to Port Harcourt to find opportunities of earning money for them.

Sadly, Port Harcourt life was a very difficult one. There were no jobs for the migrants and thus no food and hence poverty. Cost of living rose as an average one-room apartment cost N8, 000 per month. For the women, many had to resort to skills that come naturally - sex either expressed as free love or social sex for what ever accrued to it or as commercial enterprise where clients and sex workers set terms. In no time the women and girls who succeeded in the sex trade became the rural trend setters and shuttle between Port Harcourt and the country side bringing the fashion of the former to bear on the later. Soon lots of girls delve into the thriving trade.

Port Harcourt was flooded by migrants, arising from the collapse of the rural economy that sustained the people. What is more, the already collapsed agrarian sector became worsened by the pollution and devastation of farmland via oil pollution. Migrants to the city could not find jobs. Faced with joblessness and poverty of an oil economy, with oil wealth concentrated in the hands of few blacks and expatriates, females from the poor pauperized families had to seek alternative and naturally cheap means of survival- commercial sex.

Viewed from the backdrop of Marxian assumption that capitalism through the provision of jobs for women will reduce the quality and their reliance on men and their husbands, it is crystal clear that peripheral capitalist state like Nigeria is unable to resolve such inequality. Even in an Oil dominated economy, this has obvious implications for women opportunities to participate productively in the nation's economy save for the fringe areas such as commercial sex.

\section{METHODOLOGY}

The data for this study was derived from primary and secondary sources as well as literary information sources. Primary sources include face-to-face interview, questionnaire and participant observation.

Face to face interview involves physical contact with respondents through the structured and unstructured interview technique. Observation on the other hand involves observation made on hotels, night club and other major city centers where commercial sex business thrives to identify the behavior of prostitutes and those that are involved in it.

Secondary sources are made up of magazines, documentaries newspapers and library books. The simple random sampling technique was used, and from a population of 500 prostitute questionnaire was administered to 50 prostitutes and 50 others interviewed. Furthermore, from a total of 50 hotels, questionnaire was issued to 10 owners and managers of hotels and night clubs and 10 clients of prostitutes. The large number of prostitutes, hotels, and clients may generate administrative and financial difficulties if all were to be interviewed. We therefore decided to condone a large sampling error in return for speed and administrative cost reduction. 


\section{DATA ANALYSIS AND DISCUSSIONS}

The operational sample area for this study was presidential hotel junction, Tombia Street, Polo club, Worji road and Victoria Street in Port Harcourt. The area was chosen because of the high concentration of commercial sex workers activities and convenience. Being a resident of Port Harcourt and a consultant to one of the top hotels in the city, I had the privilege of observing prostitutes and their activities along this area.

Our field work unraveled the various categories into which prostitutes are classified. The categories include street girls, the amateur, the Courtesans, the Call girl, baby pro and the club girl and prostitution have attained sophistry in terms of participation, organization and practice. They have dismantled common flange, openly beckon on men and are undaunted in their activities.

Table 1

\begin{tabular}{|c|c|c|c|c|c|}
\hline Hypotheses 1 & O & E & O - E & $(\mathbf{O}-\mathbf{E}) 2$ & $\begin{array}{c}\text { (O- E)2 } \\
\text { E }\end{array}$ \\
\hline $\begin{array}{c}\text { H1 } \\
\text { There is a little rise }\end{array}$ & 55 & 65 & 10 & 100 & 1.538 \\
\hline $\begin{array}{c}\text { H0 } \\
\text { There is great rise }\end{array}$ & 75 & 65 & 10 & 100 & 1.538 \\
\hline
\end{tabular}

$\mathrm{A}-1=2-1=1$

Appropriate test techniques $=\mathrm{X} 2$ distribution

Degree of Confidence $=5 \%$

Calculated Value $=0.0796$

Critical Value $=3.84$

Since the Critical Value is greater than the calculated value, we accept the null hypotheses that there is a great rise of prostitution in Port Harcourt and thus rejecting the alternative hypotheses

Table 2

\begin{tabular}{|c|c|c|c|c|c|}
\hline Hypotheses 2 & O & E & O - E & $(\mathbf{O}-\mathbf{E}) 2$ & $\begin{array}{c}\text { (O-E)2 } \\
-------\end{array}$ \\
\hline $\begin{array}{c}\text { H1 } \\
\text { There is a little rise }\end{array}$ & 60 & 65 & 5 & 25 & 0.3846 \\
\hline $\begin{array}{c}\text { H0 } \\
\text { There is great rise }\end{array}$ & 70 & 65 & -5 & 25 & 0.7692 \\
\hline
\end{tabular}

$\mathrm{n}-1=2-1=1 \mathrm{df}$ at $5 \%$ Confidence level

$\mathrm{H} 2=$ Oil and Gas activities does not accentuate prostitution

$\mathrm{H} 0=$ Oil and Gas activities accentuate prostitution

Appropriate test technique $=\mathrm{X} 2$ distribution

Confidence level 5\%

Degree of freedom $=1 \%$ 
Calculated value $=0.7692$

Critical Value 3.84

From the statistical table above, since the critical value is greater than the calculated value we accept the null hypothesis and reject the alternative hypotheses. Therefore oil and gas exploration activities accentuate prostitution.

Table 3

\begin{tabular}{|c|c|c|c|c|c|}
\hline Factors & $\mathbf{O}$ & $\mathbf{E}$ & $\mathbf{O}-\mathbf{E}$ & $(\mathbf{O}-\mathbf{E}) \mathbf{2}$ & $\begin{array}{c}(\mathbf{O}-\mathbf{E}) 2 \\
-\mathbf{E}\end{array}$ \\
\hline $\begin{array}{c}\text { H3: } \\
\text { B }\end{array}$ & 12 & 12.5 & -0.5 & 0.25 & 0.02 \\
\hline $\begin{array}{c}\text { H3: } \\
\text { PG }\end{array}$ & 10 & 12.5 & -2.5 & 6.25 & 0.5 \\
\hline $\begin{array}{c}\text { H0: } \\
\text { P }\end{array}$ & 16 & 12.5 & 3.5 & 12.25 & 0.98 \\
\hline $\begin{array}{c}\text { H3: } \\
\text { L }\end{array}$ & 12 & 12.5 & -0.5 & 0.25 & 0.02 \\
\hline & 130 & 130 & & & \\
\hline
\end{tabular}

$\mathrm{N}-1=4-1=3 \mathrm{df}$ at $5 \%$ confidence level

$\mathrm{H} 3:=$ there is no relationship between poverty and prostitution

$\mathrm{H} 0$ : there is a relationship between poverty and prostitution

Appropriate test technique $=\mathrm{X} 2$ distribution

Confidence level $=5 \%$

Degree of freedom $=3$

Calculated value $=1.52$

Critical value $=7.81$

From the above table and calculation, since the critical value is higher than the calculated value, we accept the null hypotheses that there is a relationship between poverty and prostitution. Furthermore, of a total of 50 persons interviewed from the sample population all blame the cause of increasing prostitution in Port Harcourt to poverty.

Table 4

\begin{tabular}{|c|c|c|c|c|c|}
\hline Factors & $\mathbf{O}$ & $\mathbf{E}$ & O - E & $(\mathrm{O}-\mathrm{E}) 2$ & $\frac{(\mathrm{O}-\mathrm{E}) 2}{\mathrm{E}}$ \\
\hline $\mathrm{L}$ & 20 & 16.7 & 3.3 & 10.89 & 0.654 \\
\hline$M$ & 16 & 16.7 & 0.7 & 0.49 & 0.0293 \\
\hline $\mathrm{H}$ & 14 & 16.7 & -2.7 & 7.29 & 0.4365 \\
\hline & 50 & 50 & & & \\
\hline
\end{tabular}

$\mathrm{N}=2$ at $5 \%$ confidence level 
H4: lower income class children are less prone to prostitution

H0: Lower income class children are more prone to prostitution

Appropriate test technique $=\mathrm{X} 2$ distribution

Degree of freedom $=2$

Confidence level $=5 \%$

Calculated value $=\mathrm{X} 2=1.1179$

Critical value $=5.99$

From the critical analysis above, since the calculated value is less than the critical value, we accept the null hypotheses that lower class income children are more prone to prostitution and reject the alternative hypotheses

\section{CONCLUSION AND RECOMMENDATION}

Prostitution has become an issue of global concern, particularly in the African continent given its deleterious impact on the status of women and its threat to Africa's human resources considering its link to the world contemporary deadly diseases such as HIV AIDS and Ebola. It is even more disturbing with the recent involvement of children between the ages of 14 and 17 years referred to as child prostitution. It makes the chances our future leaders bleak. The need therefore to eradicate prostitution as an integral part of the development aspiration of most countries have produced variegated theoretical and practical attempts by policy makers, scholars and agents of social control to develop idealistic visions in the design and implementation of policies and recommendation to end prostitution.

While the prospect of ending prostitution and making women contribute meaningfully to their individual development and countries is not utopian, it is skeptical whether some of the strategies adopted towards this goal are the moves in the right direction. For instance, in a protracted effort to end prostitution in Nigeria, the federal government formulated laws against it. Section 233,224 and 225 of the criminal code point to the prohibition of the operation of brothels and soliciting for sex for money (commercial sex) a misdemeanor under public order crime. Sanctions for setting up brothels or prostitution range from 6 months to 2 years jail terms on conviction.

Furthermore, law enforcement agents particularly the police raid hotels and streets to arrest prostitutes for wandering. In Port Harcourt, prostitutes are arrested at night and detained in police stations. These strategies of tackling the problem of prostitution come dangerously to blaming the victim.

We contend that prostitution persist and increase in Port Harcourt and Nigeria at large because the root cause have not been tackled; most of the prostitutes lack the opportunity to participate productively in their economies and with ineffective voice in their societies are forced into prostitution as a survival strategy. This lack of opportunity can be located within the context of a petroleum dictated capitalist economy, its contradictions that generate and reinforce inequality and poverty. The raiding of hotels to arrest prostitutes by the police and long jail terms is misleading and worthless. Rather than deter, such measures only encourage willing minds, sympathizers of the jailed and ex-convicts to be more daring, aggressive and resilient.

Worse still, the Nigerian is police affected by the same factors that propel the prostitute into the profession. More often than not, the police arrest prostitutes and extort money from 
them for their release and some times debase-fully have sexual affairs with them in lieu of release. This is a clear contradiction indeed.

The basic issue here has to do with defective policies initiated and implemented by those in control of the instrumentalities of value distribution. Prostitution in totality has its etymology in poverty. The relegation of the agrarian sector since the discovery of oil generated an unprecedented rural urban migration. The proceeds from oil were not even channeled into productive activities by the ruling class. As if that was not enough oil and oil related activities resulted in devastation of land and pollution of rural setting. Unfortunately, even the city provided no hope: with rising unemployment and high cost living. Because these migrants to Port Harcourt do not have equal and right opportunities to actualize their aims in life they after some time turn to deviant behavior. Many young ladies are out there roaming streets unable to go to school, for those who manage to graduate jobs are not there, retrenchment is going on everyday with parents getting impoverished. It is even sad that, the same rich classes are the groups that patronize prostitutes more.

We therefore make bold the following recommendation as a practical and realistic step towards ending prostitution in Port Harcourt and in Nigeria at large.

First, the Nigerian government should re-examine the society and its institutions that have created anti-social behavior. This would mean a revolutionary programme aimed at dislodging the de-nationalized capitalist aristocracy from the control of instrumentalities of value distribution to guarantee equitable and fair distribution of national wealth for all and not for few. The re-ordering and re-appraisal of our economic system, which widens the gap between the rich and the poor, the country and the city and thus accentuate poverty is a task that must be done. In doing this our economy should be diversified with sectors articulation.

Secondly, women should have the right to participate effectively in national development activities. For centuries their contributions, given their number and strategic role in society have not been adequately acknowledged. The structures of inequality at both gender and class level must be understood, identified and tackled objectively. Furthermore, jobs should be provided for the able-bodied, food for all and people centered socio-economic policies evolved. All the laws enacted against prostitution should be made functional and efficient agencies established to punish offenders.

Lastly, solution to prostitution lies in redressing poverty and class domination, which are the main features of capitalist economies.

\section{References}

[1] Aja, A. A. (1998). Fundamentals of Modern Political Economy: International Economic Relations. Owerri, Nigeria, Globe Publishers.

[2] Asogwa, E. I. (1997). “Unemployment Problems in Nigerian Cities” Paper submitted for the $3^{\text {rd }}$ ISA World Wide Competition for young Sociologists. Australia, University of Sydney.

[3] Arkutu, A. A. (1997). Healthy Women and Healthy Mothers: An Information Guide. New York, New York Family Care International, Inc.

[4] Azunda, K. A. (1998): Sexuality and the Devaluation of Women in Nigeria in Women in Development: Evidence from Nigeria. Abak, Beltop Nigeria, Publishing Division.

[5] Brett, L. (1963): The Criminal Law and Procedure of Lagos, Eastern, and Western Nigeria. London, Sweet and Maxwell. 
[6] Bryk, K. (1964) Voodoo-Eros: Ethnological Studies in the Sex Life of the African Aborigines. New York, United Book Guild.

[7] Carmichael, K. (1982): A City and its Prostitutes. New American Magazine. New York, New York Publications.

[8] Caplan, L. (1987): Studies in Religious Fundamentalism. London, Macmillan Press

[9] Currie, E. (1998): Crime and Market Society: Lessons from the United States in Walton and Young (Eds)

[10] Ebong, O. (1989): Women Status and Health in Nigeria: in Women in Development; The Evidence from Nigeria. Abak, Belpot (Nig) Co (Publishing Division)

[11] Ekpeyong, S. (1992): The City in Africa. Lagos, African Heritage Research and Publications.

[12] Emene, F. (2012): The Prostitution Boom. Lagos, Society Magazine.

[13] Hanna, W. J. \& Hanna, J. L. (1974): Urban Dynamics in Black Africa. Chicago, Aldine, Atheston.

[14] Little, K. I., (1995): African Women in Towns. London, Cambridge University Press.

[15] Naanem, B., (1986): Itinerant Goldmines: Prostitution in the Cross River Basin (19301950). Unpublished Seminar Paper, Faculty of Humanities, University of Port Harcourt.

[16] Okoko, A. B. and Nna, N. D (1997): Federalism and resource allocation: the Nigerian experience, in Nigerian Journal of oil and Politics, Port Harcourt.

[17] Taylor, I., (1997): The Political Economy of Crime in Maguire et. Al (Eds). 